\title{
COMPARACIÓN INTERNACIONAL DE REMUNERACIONES ACADÉMICAS: UN ESTUDIO EXPLORATORIO
}

\section{Introducción}

A pesar de la importancia estratégica de la profesión académica para el desarrollo de la educación superior (OCDE, 2008), el personal docente de nivel terciario ha sido escasamente estudiado en Chile ${ }^{5}$.

Según datos del Servicio de Información de Educación Superior (SIES), ${ }^{6}$ en la actualidad hay alrededor de 90 mil docentes en el sistema en su conjunto, distribuidos entre universidades, institutos profesionales (IP) y centros de formación técnica (CFT) (Tabla 1). Los académicos universitarios, objeto del presente estudio, representan casi el 70\% del personal docente. Más de la mitad se desempeña en universidades privadas sin aporte fiscal, mientras que el $23 \%$ lo hace en universidades estatales y el $18 \%$ en universidades privadas subsidiadas directamente por el Estado (Tabla 2).

Tabla 1: Número y porcentaje de académicos por tipo de institución

\begin{tabular}{|l|c|c|}
\hline Tipo de institución & Número de académicos & Porcentaje \\
\hline CFT & 10.346 & $11 \%$ \\
\hline IP & 18.377 & $20 \%$ \\
\hline Universidades & 62.943 & $69 \%$ \\
\hline Total & 91.666 & $100 \%$ \\
\hline
\end{tabular}

Fuente: Elaboración propia basada en SIES, base de datos personal académico 2012.

5 Entre los pocos estudios recientes cabe destacar el trabajo de Bernasconi (2010), GuzmánValenzuela y Barnett (2013) y Consejo Nacional de Educación (2008).

6 El SIES pertenece a la División de Educación Superior del Ministerio de Educación y es el organismo encargado de identificar y recopilar información pública relevante para la aplicación de las políticas públicas, gestión institucional y transparencia en el sector de educación superior. Los datos sobre personal académico y matrícula son entregados por las propias instituciones al SIES en el marco de la Ley $\mathrm{N}^{\circ}$ 20.129, que establece un sistema nacional de aseguramiento de la calidad de la educación superior. Para más información sobre el SIES ver http://www.mifuturo.cl/index.php/servicio-de-informacion-de-educacion-superior/ quie y para detalles sobre las metodologías de recopilación de información de los distintos indicadores ver http://www.mifuturo.cl/index.php/metodologias/metodologias-buscadores. 
Tabla 2: Número y porcentaje de académicos por tipo de universidad

\begin{tabular}{|l|c|c|}
\hline Tipo de universidad & Número de académicos & Porcentaje \\
\hline Estatal & 14.430 & $23 \%$ \\
\hline Privada con aporte & 11.388 & $18 \%$ \\
\hline Privada sin aporte & 37.125 & $59 \%$ \\
\hline Total & 62.943 & $100 \%$ \\
\hline
\end{tabular}

Fuente: Elaboración propia basada en SIES, base de datos personal académico 2012.

Las siguientes páginas caracterizan al personal docente universitario chileno y exploran sus niveles de remuneración en función de las categorías de carrera de los académicos de jornada completa. El objetivo es proporcionar un panorama descriptivo acerca de la composición del cuerpo académico en algunas dimensiones relevantes, mostrando las diferencias existentes entre los tipos de universidades. Utilizando datos del SIES se presentan el número y distribución de académicos según jornadas laborales y género, número de instituciones en las que trabajan, sus niveles de formación y distribución regional. Luego se muestran las cifras de remuneraciones según jerarquía académica en las universidades estatales chilenas y en una muestra de universidades privadas (con y sin aporte fiscal) ${ }^{7}$.

Las remuneraciones académicas representan la proporción más alta del gasto de las universidades y son una variable determinante, aunque no la única, de las condiciones laborales de los docentes universitarios. Los salarios tienen un impacto importante sobre la calidad y el desempeño de los académicos y operan como un factor decisivo a la hora de atraer a personas altamente calificadas tanto del país como del extranjero a las universidades.

7 Los datos sobre remuneraciones fueron obtenidos mediante un estudio exploratorio desarrollado en el contexto de una investigación comparativa de más largo aliento que incluye a 28 países y es coordinada conjuntamente por el Centro para la Educación Superior Internacional del Boston College, USA, y el Laboratorio de Análisis Institucional de la Escuela de Altos Estudios Económicos de Moscú. 


\section{Perfil de los académicos universitarios}

\subsection{Jornadas laborales e instituciones}

Según la estadística oficial, los académicos universitarios chilenos trabajan 17 horas semanales en promedio. Hay, sin embargo, importantes diferencias entre los diversos tipos de universidades: los académicos de universidades privadas sin aporte poseen, en promedio, contratos por 11 horas, mientras que en las universidades estatales y privadas con aporte el promedio es de 25 y 24 horas, respectivamente. Casi no se observan diferencias entre el promedio de horas de contrato entre hombres y mujeres (Tabla 3 ).

Tabla 3: Promedio de horas de contrato por tipo de universidad, 2012

\begin{tabular}{|l|c|c|c|}
\hline & $\begin{array}{c}\text { Promedio de horas } \\
\text { contrato }\end{array}$ & $\begin{array}{c}\text { Promedio horas } \\
\text { mujeres }\end{array}$ & $\begin{array}{c}\text { Promedio horas } \\
\text { hombres }\end{array}$ \\
\hline Estatal & 24 & 24 & 24 \\
\hline Privada con aporte & 25 & 23 & 25 \\
\hline Privada sin aporte & 11 & 12 & 11 \\
\hline Total general & 17 & 17 & 17 \\
\hline
\end{tabular}

Fuente: SIES, base de datos personal académico 2012.

Aunque en Chile una jornada completa equivale a 44 horas semanales, los informes oficiales que reportan el número total de docentes universitarios consideran académicos de jornada completa a quienes tienen contratos por más de 39 o 33 horas semanales, según se consideren las bases de datos del SIES o las del Consejo Nacional de Educación (CNED) ${ }^{8}$.

El SIES utiliza la definición de la OCDE que considera como académicos de jornada completa a aquellos que trabajan semanalmente

8 Hemos optado por presentar -donde es posible- la información del SIES, ya que los datos del CNED equivalentes cubren un universo menor de universidades ( 41 de un total de 60). La clasificación del CNED considera académicos de jornada completa a aquellos que tienen contratos por un mínimo de 33 horas semanales, docentes a media jornada a aquellos que trabajan entre 20 y 32 horas semanales y profesores-hora a quienes tienen contratos por un máximo de 19 horas a la semana (CNED, 2012). Los datos del CNED indican que el $25 \%$ de los docentes universitarios tiene contratos de jornada completa. La proporción de docentes de jornada completa llega a $46 \%$ en las universidades privadas con subsidio, a $39 \%$ en las estatales y a 14\% en las privadas nuevas. Además 10\% del total de académicos universitarios trabaja en régimen de media jornada y $66 \%$ tiene contratos por un número inferior a 19 horas semanales. 
39 horas o más. Bajo este parámetro (Gráfico 1), solo 19\% de todos los académicos universitarios chilenos posee un contrato de jornada completa, oscilando entre $7 \%$ en las universidades privadas sin aporte hasta $41 \%$ en las universidades privadas con aporte (Gráfico 2). La mitad de los académicos universitarios tiene contratos por menos de 11 horas semanales, en tanto que en las universidades privadas sin subsidio dicho porcentaje asciende a $61 \%$.

Cabe destacar que la mayoría de los académicos universitarios ejerce bajo el régimen de contrato por horas y que las características y condiciones de su actividad profesional son la parte más desconocida de esta profesión académica9 ${ }^{9}$.

Gráfico 1: Distribución de académicos según régimen de contrato y tipo de universidad, 2012

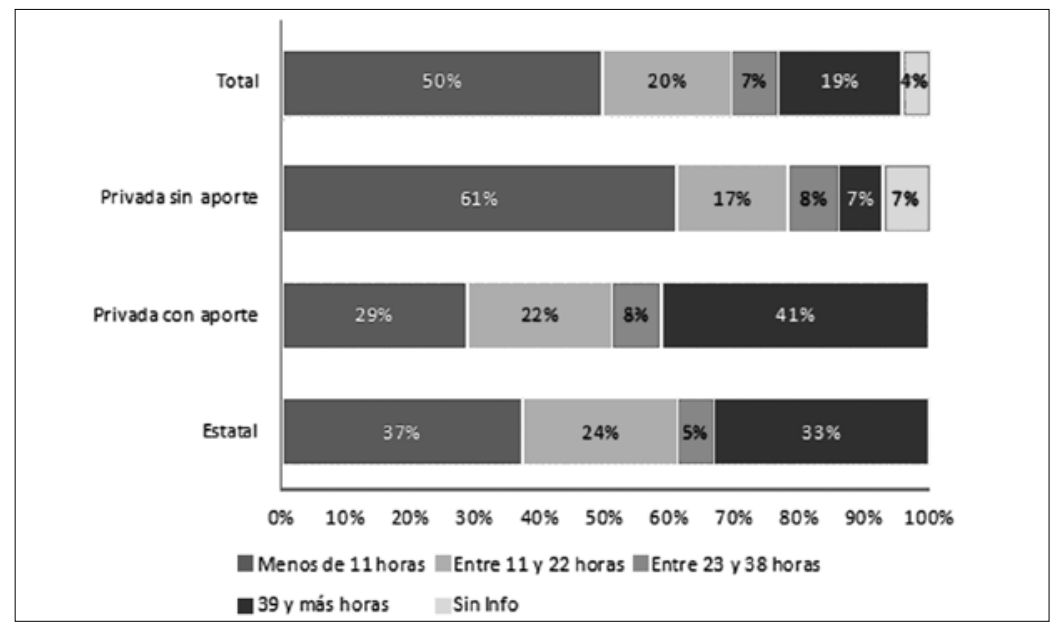

Fuente: Elaboración propia basada en SIES, base de datos personal académico 2012.

9 Para un descripción cualitativa de las condiciones contractuales y laborales de docentes universitarios part time y full time en Chile ver Guzmán-Valenzuela y Barnett (2013). En nuestro país, la Agrupación de Académicos a Honorarios de Chile (www.ahonorarios.org) se ha dedicado desde 2011 a visibilizar la situación laboral de los docentes sin contratos formales en el sistema de educación superior. En su sitio web realizan actualmente una encuesta sobre los salarios de este grupo de académicos. También en Estados Unidos las condiciones laborales y salariales del conjunto de profesores adjuntos son en gran medida desconocidas. El periódico The Chronicle of Higher Education, mediante el sitio web Adjunct Project recolecta y sistematiza información sobre dichas condiciones con la intención de hacerla pública en el futuro. Según indica el mismo sitio, en Estados Unidos dos tercios de los profesores universitarios no poseen contratos permanentes o full time. Ver http://adjunct. chronicle.com/about/ 
Gráfico 2: Académicos a jornada completa según tipo de universidad (porcentaje sobre el total de académicos en cada tipo de universidad), 2012

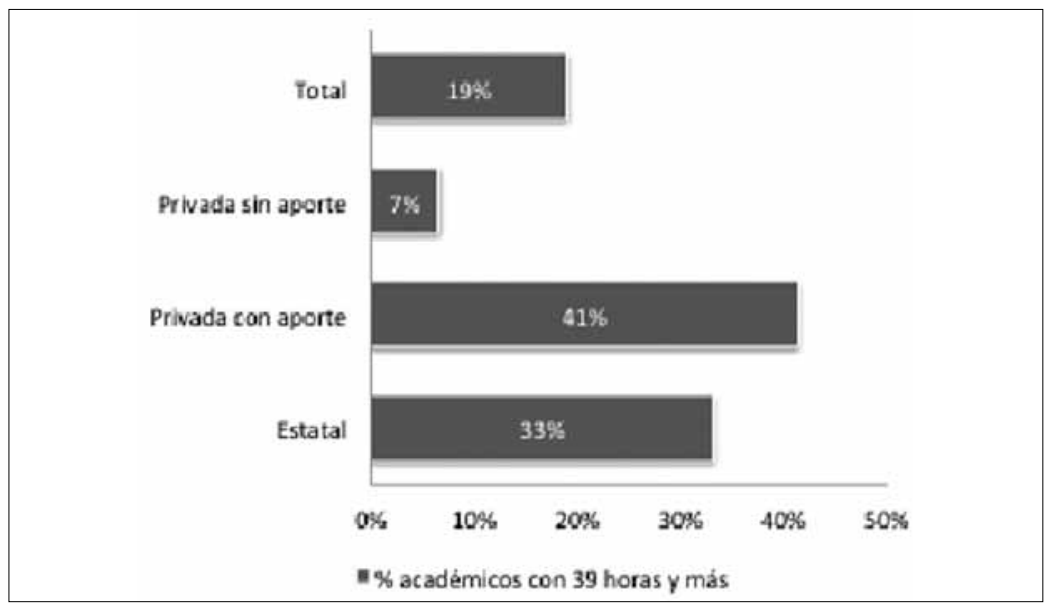

Fuente: Elaboración propia basada en SIES, base de datos personal académico 2012.

Según lo informado por las universidades al SIES, la mayoría de los académicos trabaja en una sola institución. En las universidades estatales y privadas con aporte, entre $78 \%$ y $82 \%$ de los académicos, respectivamente, se desempeña en una sola casa de estudios. En las universidades privadas sin aporte el $62 \%$ trabaja en una sola institución (Gráfico 3).

Gráfico 3: Distribución de académicos según el número de instituciones en las que trabajan y tipo de universidad, 2012

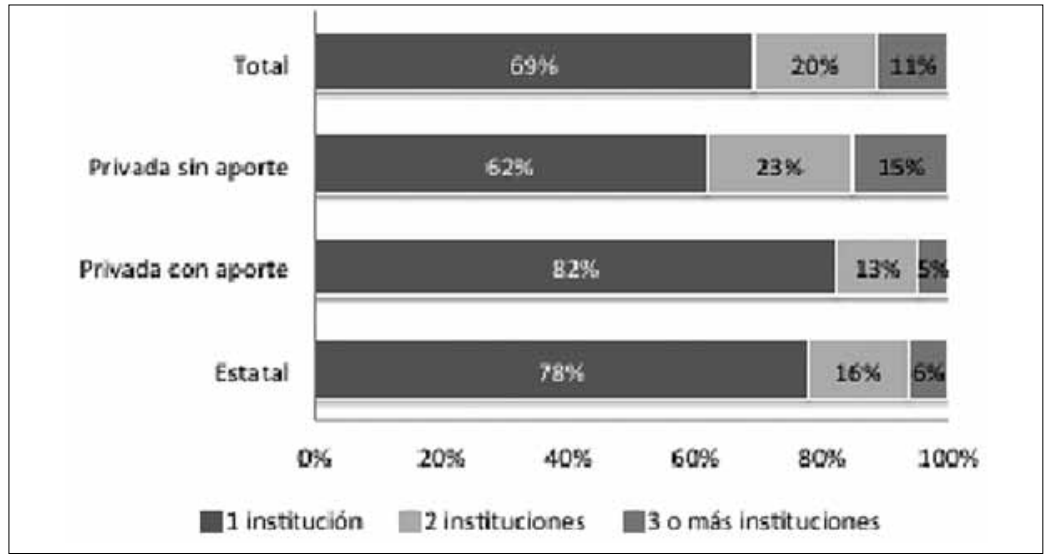

Fuente: SIES, base de datos personal académico 2012. 


\subsection{Niveles de formación}

En cuanto a calificaciones académicas, se constata que más de la mitad de los docentes universitarios carece de un posgrado. Solo el 14\% posee un doctorado, considerado progresivamente como un requisito de entrada a la carrera académica (Bernasconi, 2010). Existen, además, diferencias notorias entre los distintos tipos de universidades: mientras que en las universidades privadas con aporte el 26\% de los profesores tiene el grado de doctor, en las privadas sin aporte solo $7 \%$ posee dicho grado (Tabla 4).

Tabla 4: Porcentaje de académicos por nivel de formación y tipo de universidad

\begin{tabular}{|l|c|c|c|c|c|c|c|c|}
\hline & Doctor & Magister & $\begin{array}{c}\text { Esp. Médica u } \\
\text { Odontológica }\end{array}$ & $\begin{array}{c}\text { Licenciatura o } \\
\text { título profesional }\end{array}$ & Técnico & $\begin{array}{c}\text { Sin título } \\
\text { o grado }\end{array}$ & $\begin{array}{c}\text { Sin } \\
\text { información }\end{array}$ & Total \\
\hline Estatal & $20 \%$ & $25 \%$ & $5 \%$ & $47 \%$ & $1 \%$ & $2 \%$ & $0 \%$ & $100 \%$ \\
\hline Privada con aporte & $26 \%$ & $25 \%$ & $9 \%$ & $39 \%$ & $0 \%$ & $0 \%$ & $1 \%$ & $100 \%$ \\
\hline Privada sin aporte & $7 \%$ & $27 \%$ & $4 \%$ & $58 \%$ & $1 \%$ & $1 \%$ & $1 \%$ & $100 \%$ \\
\hline Total & $14 \%$ & $27 \%$ & $5 \%$ & $52 \%$ & $1 \%$ & $1 \%$ & $1 \%$ & $100 \%$ \\
\hline
\end{tabular}

Fuente: Elaboración propia basada en SIES, base de datos personal académico 2012.

Entre los académicos de jornada completa se puede observar que aumenta la proporción de docentes con posgrados (Gráfico 4). Un tercio posee el grado de doctor, pero esta proporción fluctúa entre el $45 \%$ en las universidades privadas con aporte y el 17\% en las privadas sin aporte. Por otro lado, $31 \%$ de los académicos de jornada completa no posee ningún tipo de posgrado o especialidad médica; cifra que asciende a $45 \%$ en universidades privadas sin aporte y a $21 \%$ en las universidades privadas con aporte. 
Gráfico 4: Niveles de formación de académicos jornada completa según tipo de universidad, 2012

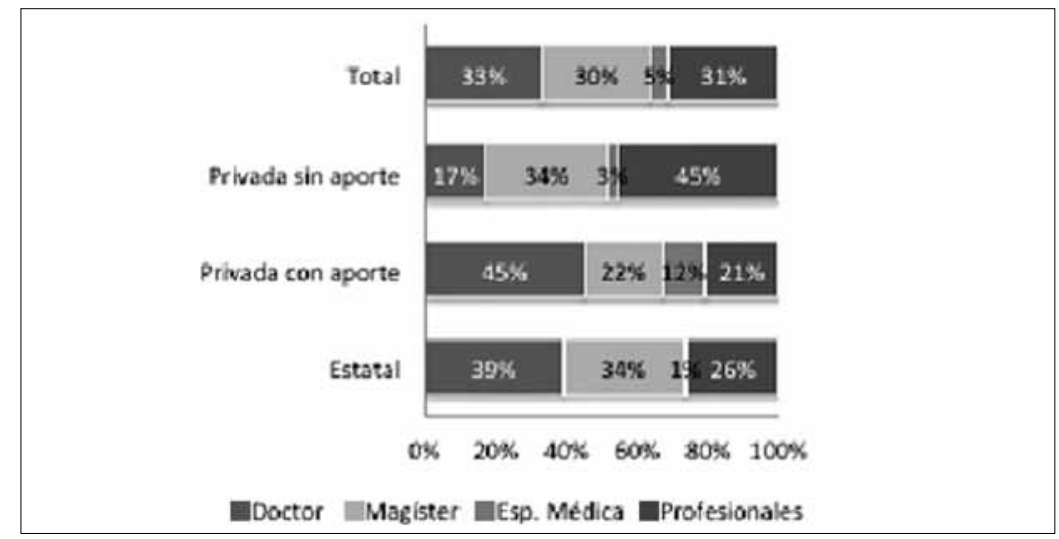

Fuente: Elaboración propia basada en índices 2012 (CNED, 2012).

Nota: Jornada completa equivale aquí a los docentes con contratos por un mínimo de 33 horas semanales.

\subsection{Composición del cuerpo académico y distribución regional}

El 40\% de los académicos son mujeres, con diferencias moderadas entre los distintos tipos de universidades (Gráfico 5). En efecto, la proporción de mujeres llega a $43 \%$ en las universidades privadas sin aporte, mientras que en las estatales y privadas con aporte representan $35 \%$ y $37 \%$, respectivamente.

Gráfico 5: Distribución de académicos por género según tipo de universidad, 2012

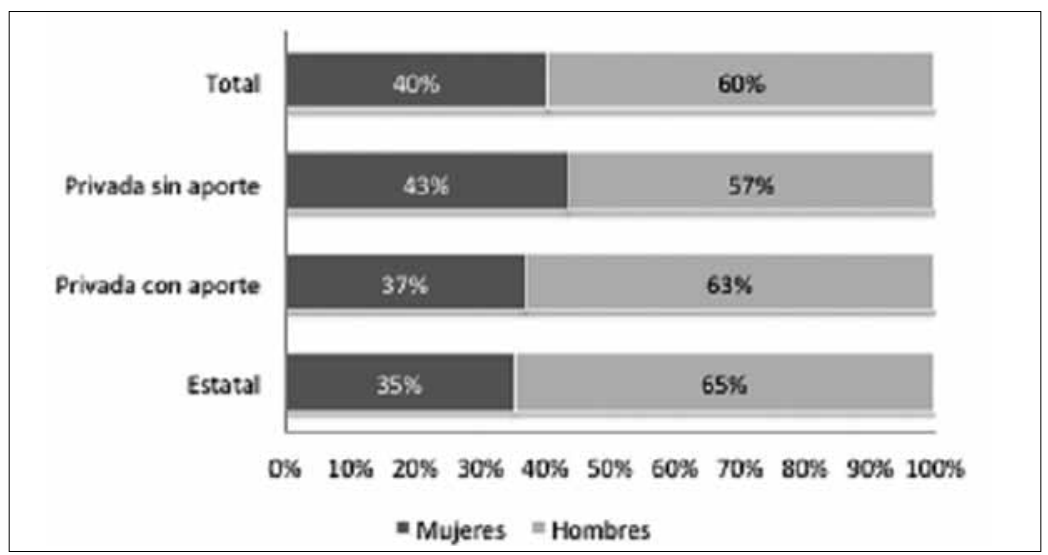

Fuente: SIES, basada en datos personal académico 2012 
Cabe mencionar que al desagregar los datos por rangos de edad se observa que en el grupo de académicos menores de 35 años la distribución según género es más equitativa, correspondiendo el 49\% a mujeres. La proporción de mujeres disminuye considerablemente a medida que aumenta la edad de los académicos y representa solo $34 \%$ en el grupo de 55 a 64 años (Tabla 5).

Tabla 5: Distribución de académicos universitarios según rango de edad, género y tipo de universidad (2012)

\begin{tabular}{|l|c|c|c|c|c|c|c|c|c|c|c|c|c|c|c|c|c|c|}
\hline & \multicolumn{3}{|c|}{ Menor de 35} & \multicolumn{3}{|c|}{ Entre $35 \mathrm{y} 44$} & \multicolumn{2}{c|}{ Entre $45 \mathrm{y} 54$} & \multicolumn{3}{|c|}{ Entre $55 \mathrm{y} 64$} & \multicolumn{3}{|c|}{ Más de 65} & \multicolumn{3}{|c|}{ Total } \\
\hline & Total & M & H & Total & M & H & Total & M & H & Total & M & H & Total & M & H & Total & M & H \\
\hline Estatal & 2.676 & $44 \%$ & $56 \%$ & 3.676 & $39 \%$ & $61 \%$ & 3.443 & $36 \%$ & $64 \%$ & 3.128 & $30 \%$ & $70 \%$ & 1.507 & $20 \%$ & $80 \%$ & 14.430 & $35 \%$ & $65 \%$ \\
\hline Privada con aporte & 2.413 & $45 \%$ & $55 \%$ & 3.459 & $40 \%$ & $60 \%$ & 2.576 & $37 \%$ & $63 \%$ & 2.029 & $31 \%$ & $69 \%$ & 897 & $17 \%$ & $83 \%$ & 11.388 & $37 \%$ & $63 \%$ \\
\hline Privada sin aporte & 10.732 & $51 \%$ & $49 \%$ & 11.951 & $43 \%$ & $57 \%$ & 7.988 & $41 \%$ & $59 \%$ & 4.503 & $39 \%$ & $61 \%$ & 1.797 & $25 \%$ & $75 \%$ & 37.125 & $43 \%$ & $57 \%$ \\
\hline Total & 15.821 & $49 \%$ & $51 \%$ & 19.086 & $41 \%$ & $59 \%$ & 14.007 & $39 \%$ & $61 \%$ & 9.660 & $34 \%$ & $66 \%$ & 4.201 & $22 \%$ & $78 \%$ & 62.943 & $40 \%$ & $60 \%$ \\
\hline
\end{tabular}

Fuente: SIES, basada en datos personal académico 2012.

Nota: Se excluye del cálculo a los académicos sin información de rango de edad.

\subsection{Distribución regional}

La distribución de docentes universitarios es similar a la distribución de la matrícula de estudiantes en este nivel institucional. Los datos recopilados por el SIES permiten ver que casi la mitad (47\%) de los académicos trabaja en la Región Metropolitana. Las otras regiones que tienen una concentración significativa de académicos son Valparaíso y Biobío (Tabla 6).

Tabla 6: Distribución de académicos por región y matrícula, 2011

\begin{tabular}{|l|c|c|l|}
\hline \multirow{2}{*}{ Región } & \multicolumn{2}{|c|}{ Académicos } & \multirow{2}{*}{$\begin{array}{c}\text { Porcentaje de } \\
\text { matrícula }\end{array}$} \\
\cline { 2 - 3 } & Número & Porcentaje & $2 \%$ \\
\hline Arica y Parinacota & 1.737 & $2 \%$ & $2 \%$ \\
\hline Tarapacá & 1.492 & $2 \%$ & $4 \%$ \\
\hline Antofagasta & 3.033 & $1 \%$ & $1 \%$ \\
\hline Atacama & 1.027 & $4 \%$ & $3 \%$ \\
\hline Coquimbo & 3.698 & $12 \%$ & $12 \%$ \\
\hline Valparaíso & 11.027 & $47 \%$ & $48 \%$ \\
\hline Metropolitana & 42.703 & $2 \%$ & $1 \%$ \\
\hline O'Higgins & 1.602 & $4 \%$ & $4 \%$ \\
\hline Del Maule & 3.763 & $12 \%$ & $13 \%$ \\
\hline Biobío & 11.182 & $4 \%$ & $5 \%$ \\
\hline La Araucanía & 3.787 & & $2 \%$ \\
\hline
\end{tabular}




\begin{tabular}{|l|r|c|c|}
\hline Los Lagos & 2.070 & $2 \%$ & $2 \%$ \\
\hline Los Ríos & 3.179 & $3 \%$ & $3 \%$ \\
\hline Aysén & 333 & $0 \%$ & $0 \%$ \\
\hline Magallanes & 1.033 & $1 \%$ & $1 \%$ \\
\hline Total & 91.666 & $100 \%$ & $100 \%$ \\
\hline
\end{tabular}

Fuente: SIES, basada en datos personal académico y datos matriculados 2012.

\section{Salarios de académicos}

El estudio sistemático de las remuneraciones académicas es incipiente a nivel internacional. La investigación que inspira este trabajo (ver nota 7) se vio limitada, entre otras cosas, por la dificultad de obtener información respecto de los salarios del personal académico universitario y la casi inexistencia de datos para las instituciones privadas, fenómeno común en casi todos los países (Altbach, Reisberg, Yudkevich, Androushchak y Pacheco, 2012).

Es usual encontrar en la literatura especializada referencias a una crisis de la profesión académica (Altbach, 2000; Enders, 2006). Se observa, por ejemplo, que la masificación de los sistemas de educación superior ha impulsado la contratación de una proporción cada vez mayor de profesores adjuntos que debe dedicarse preferentemente a tareas de docencia (en desmedro de actividades de investigación), deteriorándose las condiciones del trabajo académico (Bernasconi, 2010: 140-142). En cuanto a los salarios aparece la preocupación de que la carrera académica ya no sería atractiva para los jóvenes más talentosos y capaces en algunos países desarrollados:

En muchos países desarrollados, los salarios de académicos están cayendo por debajo de los salarios de otras profesiones que requieren un nivel educacional comparable. Países como Japón, Alemania, Israel y los Estados Unidos tendrán dificultades para atraer a los jóvenes más talentosos en el futuro, a menos de que los salarios en los rangos bajos de la jerarquía mejoren. El personal más joven es disuadido también por la creciente presión derivada de una mayor carga docente y del creciente énfasis en el número de publicaciones (Altbach et al., 2012: 12). 
También en Chile la investigación en torno a las remuneraciones académicas se halla prácticamente ausente. Se cree, sin embargo, que el aumento sostenido de las remuneraciones desde fines de la década de 1980 ha sido uno de los factores que ha contribuido a la profesionalización de la carrera académica al permitir la dedicación completa a la investigación y docencia universitaria (Bernasconi, 2010: 151).

El estudio citado de Bernasconi, basado en una muestra de doce universidades chilenas, explica asimismo que los niveles de renta varían mucho entre instituciones y que en casi todas las universidades los salarios reflejan las condiciones de mercado de las distintas disciplinas. Además, el sueldo base es complementado a menudo por remuneraciones de otras actividades profesionales como consultorías o clases de posgrado. Estas rentas variables podrían aumentar en algunos casos hasta en 50\% la remuneración base del docente.

En Chile existe un modelo bastante homogéneo de jerarquización del cuerpo académico entre las distintas universidades (Berríos, 2008). Los sistemas de jerarquización establecen una escala de remuneraciones, de modo que a mayor nivel jerárquico, mayor sueldo. Sin embargo, Berríos señala que: «El paso de una jerarquía a otra no significa necesariamente un salto cuantitativo en las remuneraciones de los profesores universitarios, sino más bien implica un cambio simbólico dentro de un sistema de prestigio» (Berríos, 2008: 45). Las cifras obtenidas para este estudio -el primero en recolectar en forma sistemática datos referidos a las remuneraciones académicas en diferentes tipos de universidades- permite discutir con base empírica algunos de estos enunciados.

\subsection{Resultados de la encuesta}

Nuestro análisis se centra en las remuneraciones mensuales brutas de los docentes de jornada completa según su jerarquía académica. Otras dimensiones relevantes como disciplina o género no son consideradas en este estudio, quedando pendientes para nuevas investigaciones en el futuro. 
La escala jerárquica de la carrera académica comprende, en la mayoría de las universidades, cuatro niveles: instructor, profesor asistente, profesor asociado y titular. Cabe mencionar que en algunas instituciones los distintos rangos jerárquicos reciben diferentes nombres y que en algunas existen más de cuatro niveles. En este último caso, para poder comparar los niveles de sueldo entre distintos rangos jerárquicos se ha optado por agregar los niveles apropiados, o bien, en algunos casos no considerarlos. También es necesario señalar que al interior de cada rango existen, en muchos casos, subcategorías que este análisis no considera.

Por mandato legal, las universidades estatales publican mensualmente las remuneraciones de todo su personal. La tabla a continuación resume la información disponible acerca de los salarios mensuales brutos de académicos de jornada completa en estas universidades ${ }^{10}$ (Tabla 7). Se observa que, en promedio, los profesores titulares de universidades estatales ganaban en el año 2012 un poco más de 2,6 millones de pesos al mes. El rango es muy amplio, siendo el sueldo más bajo en esta categoría de 1,4 millones de pesos y el más alto de 9,1 millones de pesos. En cambio, los académicos que inician su carrera (instructores) ganan en promedio 1,4 millones de pesos al mes, también con una dispersión considerable: el sueldo más bajo es inferior al millón de pesos mientras que el más alto sobrepasa los 5,6 millones de pesos.

10 En la página de transparencia de las universidades estatales se ha recopilado la información de salarios brutos mensuales de los académicos de planta y a contrata de jornada completa. Estos montos se componen de un sueldo base y varias asignaciones y bonos. En algunos casos los salarios incluyen asignaciones especiales no permanentes, como por ejemplo bonos por publicaciones ISI. En cambio, estas cifras no incluyen ningún ingreso adicional que el académico pudiera haber recibido por otras actividades profesionales, como consultorías. La Universidad de Antofagasta y la Universidad de Atacama (dos de un total de dieciséis) no presentan información respecto de la jornada de contrato de los académicos y, por lo mismo, fueron excluidas de los cálculos. 
Tabla 7: Universidades estatales. Salarios brutos mensuales, académicos jornada completa según jerarquía académica, 2012

Cifras en pesos chilenos y dólares por paridad de poder adquisitivo (US\$ PPP)

\begin{tabular}{|c|c|c|c|}
\hline \multirow{2}{*}{ Jerarquía académica } & \multirow{2}{*}{$\begin{array}{l}\text { Promedio salario bruto } \\
\text { mensual }\end{array}$} & \multicolumn{2}{|c|}{ Rango salario bruto mensual } \\
\hline & & Mínimo & Máximo \\
\hline Profesor Titular & $\begin{array}{c}\$ 2.601 .376 \\
\text { (US\$ PPP 6.702) }\end{array}$ & $\begin{array}{c}\$ 1.472 .833 \\
\text { (US\$ PPP 3.795) }\end{array}$ & $\begin{array}{c}\$ 9.176 .866 \\
\text { (US\$ PPP 23.643) }\end{array}$ \\
\hline Profesor Asociado & $\begin{array}{c}\$ 2.505 .198 \\
\text { (US\$ PPP 6.454) }\end{array}$ & $\begin{array}{c}\$ 1.000 .000 \\
\text { (US\$ PPP 2.576) }\end{array}$ & $\begin{array}{l}\$ 10.379 .549 \\
\text { (US\$26.742) }\end{array}$ \\
\hline Profesor Asistente & $\begin{array}{c}\$ 1.977 .400 \\
\text { (US\$ PPP 5.095) }\end{array}$ & $\begin{array}{c}\$ 601.853 \\
\text { (US\$ PPP 1.551) }\end{array}$ & $\begin{array}{c}\$ 9.184 .268 \\
\text { (US\$ PPP 23.662) }\end{array}$ \\
\hline Instructor & $\begin{array}{c}\$ 1.411 .909 \\
\text { (US\$ PPP } 3.638 \text { ) }\end{array}$ & $\begin{array}{c}\$ 656.911 \\
\text { (US\$ PPP 1.692) }\end{array}$ & $\begin{array}{c}\$ 5.603 .310 \\
\text { (US } \$ \text { PPP 14.436) }\end{array}$ \\
\hline
\end{tabular}

Fuente: Sobre la base de la información publicada en los sitios web de transparencia de las universidades estatales.

Notas: La información corresponde al año 2012 y solo se refiere a universidades estatales. Para 12 universidades los datos corresponden al mes de junio, para tres al mes de mayo y para una al mes de julio.

Los montos en moneda local fueron convertidos a dólares PPP utilizando la tasa de conversión de Penn World Table Version 7.1 (julio 2012) del Center for International Comparisons of Production, Income and Prices de la Universidad de Pennsylvania (1 dólar PPP equivale $\$ 388,14$ pesos chilenos).

En el caso de las universidades privadas (con y sin aporte fiscal directo) la información sobre salarios no es pública. Para efectos de nuestro análisis hemos obtenido información de un grupo de instituciones privadas con y sin aporte fiscal (Tabla 8). Se trata de un grupo heterogéneo de instituciones, las que varían en cuanto a tamaño (matrícula) y niveles de selectividad en el ingreso de los estudiantes. Solo una de ellas es de regiones ${ }^{11}$.

11 En Chile existen 44 universidades privadas con y sin aporte fiscal directo. En este estudio hemos obtenido datos de salarios por jerarquía académica para docentes de jornada completa de seis universidades privadas con y sin aporte. Cada una de las universidades privadas que compone nuestra muestra fue contactada por los investigadores de este estudio e invitadas a participar. A todas se les solicitó que proporcionaran el salario bruto mensual promedio de los académicos a jornada completa en las distintas categorías de la carrera académica de cada institución. El número total de alumnos es superior a 5.000 en todas las universidades de la muestra, pero algunas duplican o triplican esa cantidad. En cuanto a su selectividad, se utilizó como indicador el porcentaje de los 27.500 alumnos con los más altos puntajes en la Prueba de Selección Universitaria (PSU) matriculados en 2012 en cada universidad. Se observa que todas las universidades de la muestra son selectivas en algún grado; es decir, admiten al menos el 5\% de estudiantes que pertenecen a los 27.500 mejores puntajes de la PSU. Varias se encuentran en un rango de selectividad mayor, siendo la proporción de alumnos nuevos pertenecientes a los 27.500 puntajes más altos mayor al $25 \%$ y al $50 \%$. 
Tabla 8: Universidades privadas (muestra). Promedios de salarios brutos mensuales, académicos jornada completa según jerarquía académica, 2012

Cifras en pesos chilenos y dólares por paridad de poder adquisitivo (US\$ PPP)

\begin{tabular}{|c|c|c|c|}
\hline \multirow{2}{*}{ Jerarquía académica } & \multirow{2}{*}{$\begin{array}{l}\text { Promedio salario bruto } \\
\text { mensual }\end{array}$} & \multicolumn{2}{|c|}{ Rango salario bruto mensual } \\
\hline & & Mínimo & Máximo \\
\hline Profesor Titular & $\begin{array}{c}\$ 3.040 .792 \\
\text { (US\$ PPP 7.834) }\end{array}$ & $\begin{array}{c}\$ 1,740,708 \\
\text { (US } \$ \text { PPP } 4.485 \text { ) }\end{array}$ & $\begin{array}{c}\$ 7,840,074 \\
\text { (US\$ PPP 20.199) }\end{array}$ \\
\hline Profesor Asociado & $\begin{array}{c}\$ 2.396 .841 \\
\text { (US\$ PPP 6.175) }\end{array}$ & $\begin{array}{c}\$ 1,527,086 \\
\text { (US\$ PPP 3.934) }\end{array}$ & $\begin{array}{c}\$ 6,079,594 \\
\text { (US\$ PPP 15.663) }\end{array}$ \\
\hline Profesor Asistente & $\begin{array}{c}\$ 2.006 .880 \\
\text { (US\$ PPP 5.171) }\end{array}$ & $\begin{array}{c}\$ 1,262,684 \\
\text { (US } \$ \text { PPP } 3.253 \text { ) }\end{array}$ & $\begin{array}{c}\$ 5,256,532 \\
\text { (US } \$ \text { PPP } 13.543 \text { ) }\end{array}$ \\
\hline Instructor & $\begin{array}{c}\$ 1.342 .191 \\
\text { (US\$ PPP 3.458) }\end{array}$ & $\begin{array}{l}\$ 1,008,897 \\
\text { (US\$2.599) }\end{array}$ & $\begin{array}{c}\$ 2,605,200 \\
\text { (US } \$ \text { PPP } 6.712 \text { ) }\end{array}$ \\
\hline
\end{tabular}

Fuente: Muestra de universidades privadas.

Notas: Cifras calculadas sobre la base de salarios mensuales de los meses de agosto, septiembre u octubre de 2012. En el caso de una universidad se contó solo con información sobre el promedio de los salarios mensuales del año 2011. Una de las universidades en la muestra tiene solo tres jerarquías académicas (asistente, asociado y titular), por lo que las cifras para instructores no la consideran. Una de las universidades no entregó información sobre salarios mínimos y máximos.

Los montos en moneda local fueron convertidos a dólares PPP utilizando la tasa de conversión de Penn World Table Version 7.1 (julio 2012) del Center for International Comparisons of Production, Income and Prices de la Universidad de Pennsylvania (1 dólar PPP equivale \$388.14 pesos chilenos).

Los datos de universidades privadas indican que los salarios de académicos en esas instituciones se comportan de manera similar a las universidades estatales. Los sueldos promedio de cada categoría son parecidos entre ambos tipos de universidades y los profesores titulares ganan más del doble que quienes se están iniciando en la carrera académica (instructores). A su vez, dentro de cada categoría jerárquica existe un amplio margen entre los salarios más bajos y más altos. A la luz de estos datos podría concluirse, además, que los niveles de salarios son superiores (en promedio) para la jerarquía más alta en las universidades privadas ${ }^{12}$.

Algunos estudios (Berríos, 2008; Bernasconi, 2010) sugieren que los niveles de remuneraciones dependen en gran medida de las unidades académicas y disciplinarias a las que pertenecen los docentes.

12 Sin embargo, es necesario destacar que la muestra representa más bien a universidades privadas consolidadas, con planteles académicos estables y que no reflejan las condiciones de todas las instituciones que componen el sistema privado de universidades. En especial faltan en esta muestra instituciones privadas no selectivas y de carácter exclusivamente docente, un sector donde la información sobre las condiciones de trabajo y las remuneraciones de los académicos es nula. 
Efectivamente, en el caso de la Universidad de Chile, por ejemplo, el salario promedio de los profesores titulares de jornada completa de la Facultad de Economía y Negocios es prácticamente el doble al de los profesores titulares de la Facultad de Arquitectura ${ }^{13}$. Esta línea de análisis necesitaría ser profundizada en futuras investigaciones.

Por último, es claro también que existen diferencias relevantes en las remuneraciones pagadas por las universidades del sistema. El caso de las universidades estatales chilenas es interesante en este sentido, ya que en otros países las universidades públicas cuentan con escaso margen de flexibilidad para fijar los salarios de su personal. Sobre este punto ofrece algunas luces el Informe de Estados Financieros de las Universidades (segunda entrega) publicado en 2012 (Gobierno de Chile, 2012). En él se reporta el gasto en remuneraciones académicas por alumno de cada universidad. La Universidad de Chile, con 2,4 millones de pesos por alumno, es la institución que más gasta en salarios académicos. Entre las estatales, la siguen la Universidad de Talca y la Universidad Metropolitana de Ciencias de la Educación, con un gasto en salarios académicos por alumno que asciende a 1,2 millones de pesos. Con un gasto sobre el millón de pesos se encuentran además la Universidad de Magallanes, la Universidad de Santiago y la Universidad de Tarapacá. En el otro extremo, con solo 0,6 millones de pesos por alumno, se ubican la Universidad de Playa Ancha y la Universidad Arturo Prat, entre las universidades estatales.

En las universidades privadas (con y sin aporte fiscal) hay una dispersión aún mayor en este indicador. Encabeza el ranking la Pontificia Universidad Católica de Chile con un gasto en salarios académicos por alumno de 2,1 millones de pesos. La sigue la Universidad Finis Terrae con una cifra de 1,5 millones y, luego, con un gasto de entre 1,4 y 1,2 millones por alumno se encuentran las Universidades Adolfo Ibáñez, Pontificia Universidad Católica de Valparaíso, De los Andes, Austral y Diego Portales. En los últimos lugares, con un gasto en remuneraciones entre los 500.000 y 200.000 mil pesos por alumno se encuentran las Universidades Bernardo

13 La Universidad de Chile publica los datos de remuneraciones del personal de planta y a contrata según unidad académica de pertenencia. Los datos utilizados en este cálculo corresponden a noviembre de 2012. Ver www.uchile.cl/transparencia 
O'Higgins, Viña del Mar, Autónoma de Chile, UNIACC, Internacional Sek, De Las Américas, Los Leones, UCINF, Católica Cardenal Silva Henríquez, ARCIS, Miguel de Cervantes, Aconcagua y La República ${ }^{14}$.

\section{Comparación internacional de salarios de académicos en universidades públicas}

Los Gráficos 6 y 7 muestran los salarios promedio de académicos de jornada completa en universidades estatales, convertidos a dólares por paridad de poder adquisitivo (PPP por la sigla en inglés), de algunos países seleccionados. En la comparación con países de América Latina y países de ingreso medio-alto de fuera de la región -tanto en la categoría inicial como en la más alta de la carrera académica- los académicos chilenos que trabajan en universidades estatales se ubican en la parte alta de la comparación (Gráfico 6).

Gráfico 6: Universidades estatales. Salarios mensuales de académicos en jerarquía más alta e inicial en Latinoamérica y países de ingreso per cápita medio-alto

Salario promedio mensual bruto de académicos de jornada completa en US\$ PPP, 2008-2012.

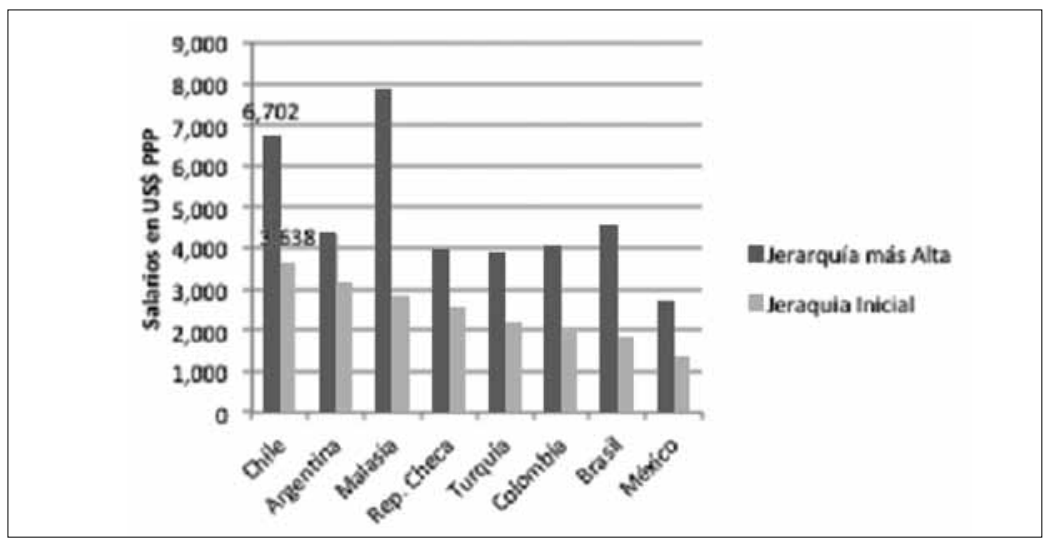

Fuente: En base al estudio «International Comparison of Academic Salaries in 28 Countries» disponible en http://acarem.hse.ru/data y para Chile, «Comparación internacional de remuneraciones académicas: un estudio exploratorio».

Nota: A excepción de Chile, los datos de salarios provienen del estudio «International Comparison of Academic Salaries in 28 Countries» que fueron recopilados entre 2008 y 2012. Para Chile, las cifras

14 Por carecer de datos no se incluyen en el informe citado: Universidad del Mar, Universidad La Araucana, Universidad de Atacama, Universidad Gabriela Mistral, Universidad Tecnológica INACAP y Universidad Católica del Maule. 
corresponden al análisis presentado en este estudio (ver Tabla 7) y corresponden a 2012. Los montos en moneda local fueron convertidos a dólares PPP utilizando las tasas de conversión disponibles en Penn World Tables 7.0 (junio 2011) y, en el caso de Chile, los pesos chilenos fueron convertidos a dólares PPP utilizando la tasa de conversión de Penn World Table Version 7.1 (julio 2012) del Center for International Comparisons of Production, Income and Prices de la Universidad de Pennsylvania. Los países están ordenados de mayor a menor salario en jerarquía inicial y luego de mayor a menor salario en jerarquía más alta.

Si la comparación se realiza con otros países de ingreso alto, los salarios de los docentes chilenos se sitúan tanto en la categoría más alta como en la inicial, en un nivel intermedio: por encima de Francia, Japón e Israel y por debajo de Canadá, Estados Unidos, Italia, Holanda, el Reino Unido y Australia (Gráfico 7).

Gráfico 7: Universidades estatales. Salarios mensuales de académicos en jerarquía más alta e inicial de la carrera académica en países de ingreso per cápita alto.

Salario promedio mensual bruto de académicos de jornada completa en US\$ PPP, 20082012

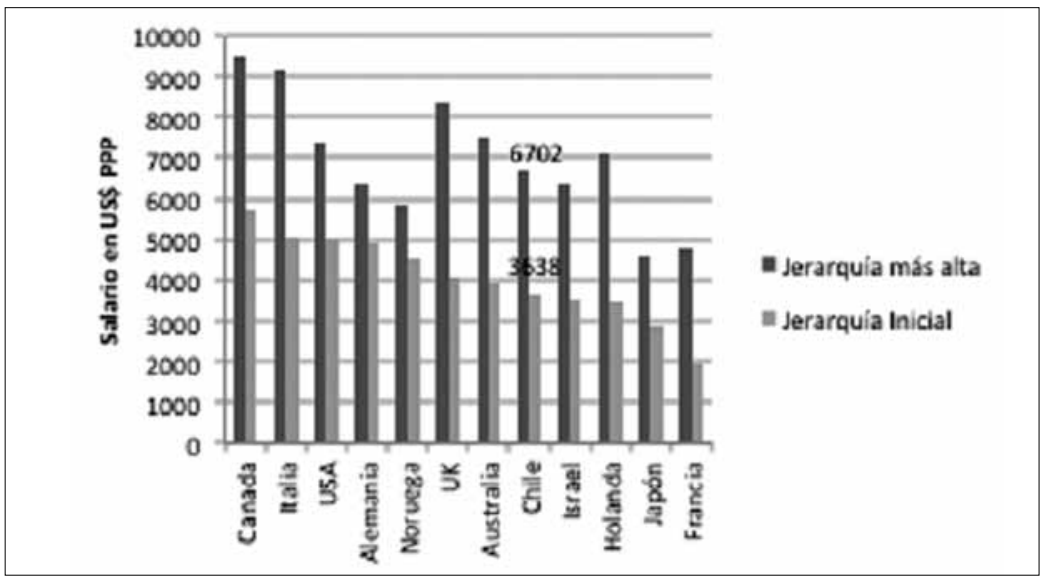

Fuente: En base al estudio «International Comparison of Academic Salaries in 28 Countries» disponible en http://acarem.hse.ru/data y para Chile, «Comparación internacional de remuneraciones académicas: un estudio exploratorio».

Nota: A excepción de Chile, los datos de salarios provienen del estudio «International Comparison of Academic Salaries in 28 Countries» que fueron recopilados entre 2008 y 2012. Para Chile, las cifras corresponden al análisis presentado en este estudio (ver Tabla 7) y corresponden a 2012. Los montos en moneda local fueron convertidos a dólares PPP utilizando las tasas de conversión disponibles en Penn World Tables 7.0 (junio 2011) y, en el caso de Chile, los pesos chilenos fueron convertidos a dólares PPP utilizando la tasa de conversión de Penn World Table Version 7.1 (julio 2012) del Center for International Comparisons of Production, Income and Prices de la Universidad Pennsylvania. Los países están ordenados de mayor a menor salario en jerarquía inicial y luego de mayor a menor salario en jerarquía más alta. 
Los datos revisados muestran las brechas existentes entre los salarios de los académicos al inicio y al final de la carrera. El estudio internacional de Altbach et al. (2012) muestra que la progresión en las remuneraciones a lo largo de la carrera académica varía considerablemente en los diferentes países. Entre las naciones estudiadas, China obtiene la brecha más amplia: los académicos en la jerarquía más alta ganan en promedio 4,3 veces más que los que se encuentran en el escalafón inicial. En el otro extremo, la diferencia se reduce a 1,3 veces en Noruega.

Chile muestra una brecha moderada en comparación con los otros países que componen el estudio internacional. En las universidades estatales los académicos titulares ganan, en promedio, 1,8 veces el salario de un académico instructor. En Argentina, el país latinoamericano con la menor brecha, la razón entre las remuneraciones de titulares e instructores es 1,4, en Brasil 2,1 y en Colombia y México, 2,0 (Altbach et al., 2012: 29).

En síntesis, los salarios de los académicos de jornada completa en Chile son relativamente altos a nivel internacional y la brecha entre los profesionales que inician su carrera y aquellos que han alcanzado el escalafón jerárquico más alto es moderada.

Altbach et at., señalan que «los salarios son atractivos en aquellos países en que la remuneración para la jerarquía más alta es elevada y la brecha con los salarios de los académicos del nivel inicial es pequeña» (Altbach et al., 2012: 9). Según los datos aquí presentados, Chile se encuentra en un escenario como el recién descrito. Un signo adicional de que la carrera académica es atractiva desde el punto de vista salarial es que se incorporan cada vez más docentes extranjeros a nuestro sistema de educación superior. Según datos del SIES, los profesores extranjeros representan hoy a 3,8\% del total de académicos en la educación superior, mientras que en 2008 representaban a 2,5\% (Salazar, 2013) ${ }^{15}$.

15 Se han dado, además, casos excepcionales como el de la Universidad Autónoma, institución que ha incorporado a su planta a 100 académicos extranjeros con doctorado en 2013 (EFE 2013). 
Gracias a los datos sobre ingresos de los graduados de la educación superior proporcionados por el sitio mifuturo.cl, en Chile es posible también comparar la remuneración de los académicos con las de otros profesionales universitarios en los años iniciales de sus trayectorias laborales.

Utilizando esa información, Meller (2010: 64) concluye que las carreras más rentables en el país son Ingeniería Comercial, Ingeniería Civil e Industrial y Medicina. Los datos de mifuturo.cl ${ }^{16}$ indican que a los cinco años de egresados (comparable al tiempo que en general demoran los graduados en alcanzar la categoría de instructores), los salarios promedio bordean, en estas carreras, los dos millones de pesos al mes (con la excepción de Ingeniería Civil en Minas, que se acerca a los tres millones). Al otro lado, los egresados de las carreras de más bajos ingresos en el estudio de Meller (Actuación Teatral, Educación Parvularia y algunas Pedagogías) obtienen remuneraciones al quinto año de egreso que, en promedio, bordean los 500 mil pesos. Los académicos en la categoría de instructores, con un salario promedio que supera los 1,3 millones de pesos se ubicarían en un nivel intermedio dentro de esta distribución, en un nivel similar al de los egresados de Construcción Civil o Ingeniería Mecánica.

En suma, igual como se establece para los países analizados en el estudio de Altbach et al. (2012), también en Chile existen para los jóvenes profesiones con salarios más altos que los ofrecidos por la academia. Además hay profesiones en las que las remuneraciones, luego de cinco años contados desde el egreso de la universidad, se acercan al promedio de lo que ganan los profesores titulares. Cabe tener en cuenta, sin embargo, la alta variabilidad en las remuneraciones al interior de cada jerarquía académica (Tabla 7) y estudiar en forma más detallada las variables que explican esa dispersión.

16 Estadísticas por carrera 2013 disponible en http://www.mifuturo.cl/index.php/bases-dedatos/mi-futuro (recuperado el 2-10-2013) 


\section{Conclusiones}

Los datos acerca de las remuneraciones académicas recopilados para este estudio corresponden a los de docentes de jornada completa de 14 de las 16 universidades estatales de nuestro sistema y de una muestra de seis universidades privadas con y sin aporte fiscal. A su turno, los académicos con contratos de jornada completa representan el 19\% del total de docentes universitarios.

Los salarios de estos académicos pueden llegar a doblarse a lo largo de la trayectoria profesional. En las universidades estatales un profesor instructor gana en promedio 1,4 millones de pesos mensuales, mientras que un profesor titular gana, en promedio, 2,6 millones. En nuestra muestra de universidades privadas, la diferencia entre el nivel inicial y el más alto de la jerarquía académica es mayor, promediando 1,3 millones mensuales los profesores instructores y tres millones mensuales los titulares.

Las remuneraciones de los académicos universitarios full time de las universidades estatales chilenas, tanto al inicio como al tope de la carrera académica, son altos en el contexto latinoamericano y de otros países de ingreso medio-alto de otras regiones, mientras que comparados con países desarrollados de ingreso alto, los salarios de los académicos chilenos se ubican en un nivel intermedio.

Este estudio exploratorio sugiere una agenda futura de investigación, dentro de la cual destacan algunos temas. En un sistema altamente diversificado como el chileno se requiere profundizar el análisis de la estructura de la profesión académica y cómo se halla estratificada según tipo de universidad, tipo de contrato (jornada) y selectividad o prestigio de la institución. Por ejemplo, hay signos de que las condiciones salariales y laborales de los académicos que se desempeñan en universidades privadas de baja selectividad y de menor prestigio, muchos de ellos con contratos por hora, están precarizadas. Igualmente interesa conocer mejor las diferencias salariales según áreas disciplinarias $\mathrm{y}$, aunque no ha sido tratado aquí, el impacto que los diversos incentivos salariales tienen sobre las remuneraciones y niveles de satisfacción de los docentes respecto 
de su profesión. Asimismo, parece de interés estudiar los efectos de la competencia entre instituciones sobre los salarios de los diversos niveles jerárquicos de la carrera académica y, también, sobre la atracción de personal docente proveniente del extranjero.

\section{Referencias bibliográficas}

Altbach, P. G., (2000) «The Deterioration of the Academic Estate: International Patterns of Academic Work». En The Changing Academic Workplace: Comparative Perspectives, P. G. Altbach (ed.) Chestnut Hill, Massachusetts: Center for International Higher Education, Lynch School of Education, Boston College, pp. 1-23.

Altbach, P. G., Reisberg, L., Yudkevich, M., Androushchek, G. e I. Pacheco, (2012) Paying the Professoriate. A Global Comparison of Compensation and Contracts, New York: Routledge.

Bernasconi, A., (2010) «La apoteosis del investigador y la institucionalización de la profesión académica en Chile», en ESE Estudios sobre Educación, 19, diciembre, pp. 139-163. [En línea], disponible en: http://www. ceppe.cl/images/stories/articulos/educacion-superior/Desarrollo_de_ la_profesin_acadmica_en_Chile.pdf [Recuperado 13 de septiembre de 2012].

Berríos, P., (2008) «Carrera académica: análisis empírico de su estructura y organización en Chile». Calidad en la Educación, 29, diciembre, pp. 36-62. [En línea], disponible en: http://www.cned.cl/public/secciones/ SeccionRevistaCalidad/doc/60/cse_resumen739.pdf [Recuperado 13 de septiembre de 2012].

Consejo Nacional de Educación, (2008) Calidad en la Educación: La profesión académica, 28, ler semestre. [En línea], disponible en http://www. cned.cl/public/Secciones/SeccionRevistaCalidad/revista_calidad_leer_ revista. aspx?idPublicacion=59 [Recuperado 3 de octubre de 2013].

Consejo Nacional de Educación, (2012) Docentes 2012, Santiago, Chile. [En línea], disponible en: http://www.cned.cl/public/Secciones/ SeccionIndicesEstadisticas/doc/NovEstadisticas2012/008_Web_ Docentes.pdf. [Recuperado 3 de octubre de 2013].

Enders, J., (2006) «The Academic Profession». En International Handbook of Higher Education, J.F. Forest y P. Altbach, (eds.) Springer Netherlands, pp. 5-21.

Gobierno de Chile, (2012) Estados financieros de las universidades. Segunda entrega, Gobierno de Chile. [En línea], disponible en http://www. 
consejoderectores.cl/web/pdf/Acta_537/Anexos_537/Estados_ financieros_Universidades.pdf. [Recuperado 13 de septiembre de 2012].

Guzmán-Valenzuela, C. y R. Barnett, (2013)«Academic Fragilities in a Marketised Age: The Case of Chile». British Journal of Educational Studies, Vol 61, N² 2, pp.203-220. [En línea], Ddisponible: http:// www.tandfonline.com/doi/abs/10.1080/00071005.2013.776006 [Recuperado 22 de agosto de 2013].

Meller, P., (2010) Carreras universitarias. Rentabilidad, selectividad y discriminación. Santiago: Uqbar Editores.

OCDE, (2008) Tertiary Education for the Knowledge Society. OECD thematic review of tertiary education: synthesis report. Paris. [En línea], disponible en: http://www.voced.edu.au/content/ngv20398 [Recuperado 5 de noviembre de 2012].

Salazar, P., (2013) Profesores extranjeros en Universidades e institutos chilenos suben 39\% entre 2008 y 2012. La Tercera, [online] 22 de julio. Disponible en: http://diario.latercera.com/2013/07/22/01/ contenido/pais/31-142240-9-profesores-extranjeros-en-universidadese-institutos-chilenos-suben-39-entre.shtml [Recuperado: 1 de agosto de 2013].

Recibido: 8/10/2013

Aceptado: 18/11/2013 